\title{
Stroke Involving the Percheron Artery: A Rare Anatomical Variant
}

\author{
Sana Najib ${ }^{\mathrm{a}, \mathrm{b}}$, Ali Nadhimª, Tahmina Saleemª, Behzad Amoozgar ${ }^{\mathrm{a}}$, \\ Shuvendu Sen ${ }^{\mathrm{a}}$
}

\begin{abstract}
Artery of Percheron is a rare anatomical variant of posterior cerebral circulation. Stroke involving this artery causes characteristic bilateral thalamic infarcts. Here, we report a case of artery of Percheron infarction in a 53-year-old man with hypertension and diabetes. Our case highlights the importance of raising our awareness about the artery of Percheron and the prompt recognition of its infarction by pursuing appropriate imaging studies to allow timely administration of thrombolysis. Reversal of a potential damaging neurological insult and subsequent favorable clinical improvement are the expected outcomes.
\end{abstract}

Keywords: Artery of Percheron stroke; Posterior circulation variant; Bilateral thalamic infarcts

\section{Introduction}

Posterior cerebral circulation hosts few anatomical variants. Commonly the paramedian territory of the thalamus is supplied by perforating arteries arising from ipsilateral posterior cerebral arteries, but very rarely all perforating branches arise from one posterior cerebral artery through a single trunk called the artery of Percheron. This variant represents $0.1-2 \%$ of total ischemic strokes and of thalamic strokes, this artery is the cause for $4-10 \%$ of presented cases [1-4].

\section{Case Report}

A 53-year-old male, with a past medical history of diabetes mellitus and hypertension, presented to the emergency department (ER) with the chief complaint of "right leg weakness and difficulty walking" since the last $8 \mathrm{~h}$. The patient worked in

Manuscript submitted August 19, 2018, accepted September 24, 2018

a Jersey Shore University Medical Center, Perth Amboy Division, Perth Amboy, NJ, USA

${ }^{\mathrm{b} C}$ Corresponding Author: Sana Najib, Jersey Shore University Medical Centre, Perth Amboy, NJ 08861, USA. Email: sananajib@yahoo.com

doi: https://doi.org/10.14740/jnr494w a transportation company and he was pushing a wheelchair when he noticed that he was dragging his right leg. Then when signing the patient's arrival in his transport, he had trouble in signing. When he was sent to the hospital, he developed tingling and numbness of right hand.

On arrival to ER, vital signs were: blood pressure (BP) of $190 / 85 \mathrm{~mm} \mathrm{Hg}$, pulse of $89 / \mathrm{min}$, respiratory rate of 20 / min and temperature of $97.7^{\circ} \mathrm{F}$. On neurological examination, power was $3 / 5$ in the right leg and right arm. Sensations to pinprick were decreased on the right arm. The rest of examination was within normal limits. Initial lab work showed white blood cell (WBC) count of $5.9 \times 10^{3} / \mathrm{mL}$, hemoglobin of $14 \mathrm{~g} / \mathrm{dL}$, hematocrit of $42.4 \%$, platelets of $164 \mathrm{k} / \mu \mathrm{L}$, blood urea nitrogen (BUN) of $8 \mathrm{mg} / \mathrm{dL}$, creatinine of $1 \mathrm{mg} / \mathrm{dL}$, glucose of $305 \mathrm{mg} / \mathrm{dL}$, sodium of $136 \mathrm{mmol} / \mathrm{L}$ and potassium 3.8 $\mathrm{mmol} / \mathrm{L}$.

Code stroke was called and a head CT scan was done that was negative for any bleed or ischemia. The patient was admitted to the stroke unit and the next day, the MRI of the brain showed bilateral thalamic infarcts (Fig. 1). The characteristic infarct pattern prompted a need for CT angiography (CTA) of head and neck which was negative for any largevessel occlusion, any high-grade stenosis or any aneurysm, but revealed a filling defect in the artery of Percheron suggestive of occlusion. He was started on non-tissue plasminogen activator (tPA) protocol for stroke treatment as he was out of window for tPA. Aspirin and statin along with physical therapy were started and over the next few days, patient's neurological symptoms improved and he was discharged home.

\section{Discussion}

Artery of Percheron infarcts is rare. It typically presents with altered mental status, hemiplegia and gaze palsy [5], but because of complex anatomy and different variants of posterior cerebral circulation, ischemic infarcts in this territory usually present with variable and non-specific symptoms, which often delays the clinical diagnosis $[5,6]$. An initial head CT scan in most cases of artery of Percheron strokes shows no ischemia $[7,8]$. MRI has the best sensitivity for the diagnosis of posterior circulation strokes. On clinical suspicion, thus, it should be the first investigation of choice followed by CTA of head and neck. These would allow the infarct to be identified at an early stage and treatment with thrombolysis or mechanical canaliza- 


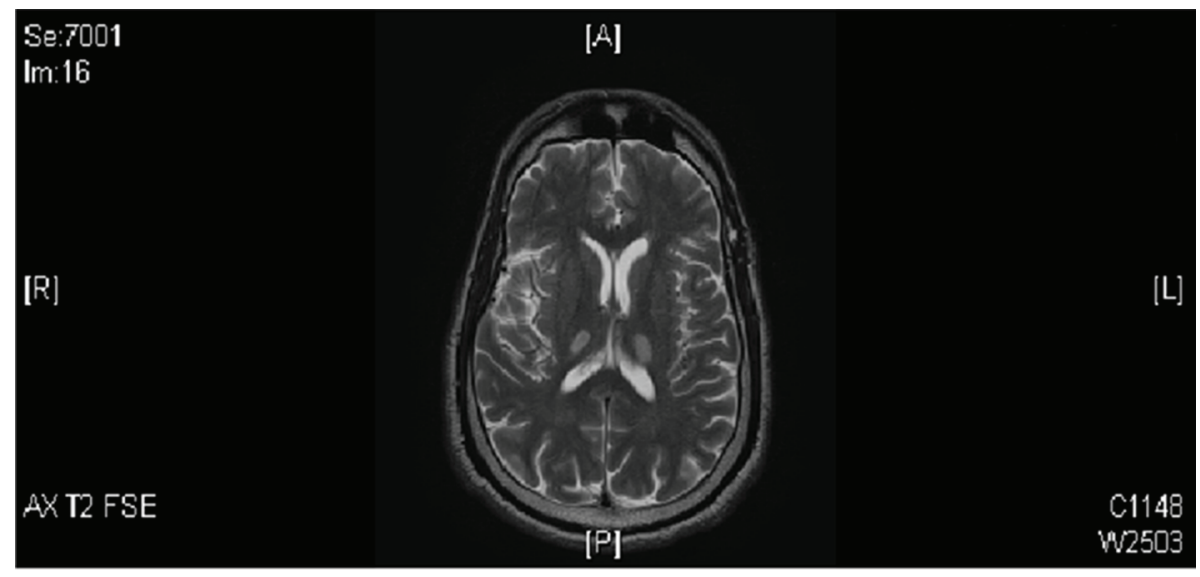

Figure 1. MRI brain showing bilateral thalamic infarcts.

tion can save the reversibly damaged brain tissue [9]. Further review of literature regarding strokes involving the artery of Percheron reveals cases where the MRI was initially negative. In the right clinical context, it may be necessary to do serial MRIs [10].

\section{Conclusions}

Our case highlights the importance of raising our awareness about the artery of Percheron and the prompt recognition of its infarction by pursuing appropriate imaging studies to allow timely administration of thrombolysis [9]. Reversal of a potential damaging neurological insult and subsequent favorable clinical improvement are the expected outcomes.

\section{Conflict of Interest}

The authors declare that they have no competing interests.

\section{Author Contributions}

SN and TS managed the patient. AN and SN drafted the initial manuscript which was modified and reviewed by BA and SS. All authors read and approved the final manuscript.

\section{Consent to Participate}

The patient provided informed, written consent for participation.

\section{Consent for Publication}

Written informed consent was obtained from the patient for publication of this case report and any accompanying images. A copy of the written consent is available for review by the Editor-in-Chief of this journal.

\section{References}

1. Agarwal N, Chaudhari A, Hansberry DR, Prestigiacomo CJ. Redefining thalamic vascularization vicariously through gerald percheron: a historical vignette. World Neurosurg. 2014;81(1):198-201.

2. Lazzaro NA, Wright B, Castillo M, Fischbein NJ, Glastonbury CM, Hildenbrand PG, Wiggins RH, et al. Artery of percheron infarction: imaging patterns and clinical spectrum. AJNR Am J Neuroradiol. 2010;31(7):1283-1289.

3. Lamot U, Ribaric I, Popovic KS. Artery of Percheron infarction: review of literature with a case report. Radiol Oncol. 2015;49(2):141-146.

4. Sandvig A, Lundberg S, Neuwirth J. Artery of Percheron infarction: a case report. J Med Case Rep. 2017;11(1):221.

5. Amin OS, Sa'ad Seud Shwani HM, Zangana EM, Ameen NA. Rare disease: Bilateral infarction of paramedian thalami: a report of two cases of artery of Percheron occlusion and review of the literature. BMJ case reports. 2011;2011.

6. Stamm BJ, Lineback CM, Skolarus LE, Morgenstern LB, Shah GV. Artery of Percheron infarct: 12 cases and their complex clinical courses. Neurohospitalist. 2018;8(3):141145.

7. Shea YF, Lin OY, Chang RS, Luk JK. Artery of Percheron infarction. Hong Kong Med J. 2012;18(5):446 e441-442.

8. Raphaeli G, Liberman A, Gomori JM, Steiner I. Acute bilateral paramedian thalamic infarcts after occlusion of the artery of Percheron. Neurology. 2006;66(1):E7.

9. Ahmad N, Nayak S, Jadun C, Natarajan I, Jain P, Roffe C. Mechanical thrombectomy for ischaemic stroke: the first UK case series. PLoS One. 2013;8(12):e82218.

10. Xu Z, Sun L, Duan Y, Zhang J, Zhang M, Cai X. Assessment of Percheron infarction in images and clinical findings. J Neurol Sci. 2017;383:87-92. 